\title{
PEDAGOGIA UNIVERSITÁRIA E APRENDIZAGEM DOCENTE: relações e novos sentidos da professoralidade
}

\author{
University pedagogy and docent learning: \\ relations and new significations of \\ professorship
}

Doris Pires Vargas Bolzan ${ }^{[a]}$, Silvia Maria de Aguiar Isaia ${ }^{[b]}$

[a] Coordenadora e professora do Programa de Pós-Graduação em Educação, Universidade FederaldeSantaMaria(UFSM), SantaMaria,RS-Brasil, e-mail:professoradoris@smail.ufsm.br [b] Professora do Programa de Pós-Graduação em Educação e Professora do Mestrado Profissionalizante em Ensino de Física e Matemática, Universidade Federal de Santa Maria (UFSM), Santa Maria, RS - Brasil, e-mail: sisaia@terra.com.br

\section{Resumo}

Este artigo trata de estudos relativos à pedagogia universitária e à aprendizagem docente, buscando explicitar as relações e os novos sentidos da professoralidade. Assim refletir sobre as formas de intervenção pedagógica pode contribuir para a construção da professoralidade à medida que esse processo reflexivo possibilita responder a determinadas condições, compreendendo a experiência

Rev. Diálogo Educ., Curitiba, v. 10, n. 29, p. 13-26, jan./abr. 2010 
como princípio e não como momento de culminância da aprendizagem docente. Inferimos, pois, que os alicerces constitutivos à pedagogia universitária são a reflexão individual e coletiva, as relações intersubjetivas e interdiscursivas e o conhecimento pedagógico compartilhado que se consubstanciam no ato de aprender a ser professor. Portanto, a pedagogia universitária pode ser pensada como um campo em construção, no qual podemos analisar e compreender os fenômenos de aprender e de ensinar as profissões e, sobretudo, um lugar no qual a docência universitária em ação pode ser revisitada e reconstruída. Nesse sentido, ao analisarmos o contexto universitário, buscamos encontrar formas genuínas de construção de saberes capazes de dinamizar as inovações e a difusão de experiências, considerando o contexto global e local, no qual o processo pedagógico se institui. Enfim, acreditamos que esse espaço constitui-se em um lugar de formação no qual o protagonismo pedagógico é reconhecido como caminho para emancipação dos processos formativos, da aprendizagem de ser professor e da construção da professoralidade.

Palavras-chave: Pedagogia universitária. Aprendizagem docente. Professoralidade. Docência superior. Processos formativos.

\begin{abstract}
This article relates to the university pedagogy and the docent learning that is searching to clarify the relations and the new significations of professorship. Thus, reflecting about the manners of pedagogical intervention can contribute to the construction of professorship as this reflexive process can answer to specific conditions perceiving the experience like the beginning - it is not the moment of the highest point of the docent learning. We infer that the essential bases for the university pedagogy are the individual and collective reflection, inter subjective and inter discursive relations and the shared pedagogic knowledge that consubstantiate at the act of learning to be a professor. Therefore, the university pedagogy can be thought as a field in construction in which we can analyze and understand the phenomena of learning and teaching the
\end{abstract}

Rev. Diálogo Educ., Curitiba, v. 10, n. 29, p. 13-26, jan./abr. 2010 
professions, above all, a place that the university teaching in action can be rebuilt. In such case, analyzing the university context we searching to find genuine forms of knowledge construction able to become dynamics the innovations and the diffusion of experiences, considering the global and local context in which the pedagogic process sets up. Finally, we believe that this space is constituted by a formation place in which the pedagogic protagonism is recognized as a way to the emancipation of the formative processes of the learning of being professor and the construction of professorship.

Keywords: University pedagogy. Docent learning. Professorship. Superior teaching. Formative processes.

\section{PRIMEIRAS PALAVRAS}

Neste artigo abordamos estudos relativos à pedagogia universitária e à aprendizagem docente que nos remetam à compreensão das relações e dos novos sentidos da professoralidade, no contexto da educação superior.

Nessa perspectiva, entendemos que a pedagogia universitária caracteriza-se por ser um campo disciplinar em construção, que vem sendo consolidado como parte de um conjunto de práticas com características próprias, por meio de processos de fazer e pensar a ação docente e sua repercussão nos processos formativos para a docência, assumindo-se como um campo gerador de diversidade (LUCARELLI, 2007; BOLZAN, 2008).

Desse modo, a ideia de aprendizagem docente constitui-se como elemento basilar da pedagogia universitária, na medida em que se consolida a partir da articulação entre modos de ensinar e de aprender, permitindo aos atores desse processo intercambiarem essas funções, tendo o conhecimento profissional compartilhado e a aprendizagem colaborativa (ISAIA, 2006b) como condição para o desenvolvimento e concretização do fazer-se professor ao longo da trajetória pessoal e profissional. Essa condição implica a possibilidade do docente estar aberto e receptivo a aceitar novas formas de constituir-se, tanto em termos de conhecimentos específicos, quanto pedagógicos e experienciais.

Logo, acreditamos que, compreendendo quais concepções os professores têm sobre suas práticas nesse nível de ensino e como estas

Rev. Diálogo Educ., Curitiba, v. 10, n. 29, p. 13-26, jan./abr. 2010 
se consolidam ao longo de sua formação profissional, é possível a reconstrução das bases epistemológicas, capazes de colaborar para o entendimento do processo de apreender a docência. Nesse contexto, é imprescindível reconhecermos o processo de construção pedagógico e epistemológico como contínuo, envolvendo o que os professores veem, o que acreditam e o que fazem, compreendendo a experiência como princípio e não como momento de culminância de suas aprendizagens. Ao mesmo tempo, não podemos falar em aprendizagem docente sem referência aos discentes em seus processos formativos, pois, à medida que os professores são formadores, também se formam.

A construção da aprendizagem de ser professor, portanto, é colaborativa, faz-se na prática de sala de aula e no exercício de atuação cotidiana da universidade. É uma conquista social, compartilhada, que envolve trocas e representações. Com essa postura, o professor está produzindo sua professoralidade, o que implica não só em dominar conhecimentos, saberes, fazeres de determinado campo, mas também na sensibilidade em termos de atitudes e valores que levem em conta os saberes da experiência. Esta, contudo, precisa ser entendida a partir de uma ótica de reflexão sistemática na qual o foco está nas relações interpessoais, componente intrínseco ao processo de ensinar, aprender, formar-se e, consequentemente, desenvolver-se profissionalmente.

\section{Discutindo a temática}

A discussão acerca do campo temático sobre o qual nos debruçaremos decorre dos estudos de Isaia (2003, 2004, 2006a, 2006b, 2007a, 2008) e Bolzan (2001, 2002, 2004, 2005, 2006, 2007, 2008) relativos à pedagogia universitária, a aprendizagem docente e a construção da professoralidade.

O aprofundamento dessa discussão remete-nos em primeiro lugar à retomada do conceito de pedagogia universitária entendida como um campo de aprendizagem da docência que envolve a apropriação de conhecimentos, saberes e fazeres próprios ao magistério superior, estando vinculados à realidade concreta da atividade de ser professor em seus diversos campos de atuação e em seus respectivos domínios. Assim, o impulso que direciona a aprendizagem docente é representado por sentimentos que indicam sua finalidade geral, bem como o estabelecimento de objetivos específicos, a partir da compreensão do ato educativo (ISAIA, 2007a, 2008).

Rev. Diálogo Educ., Curitiba, v. 10, n. 29, p. 13-26, jan./abr. 2010 
Corroborando com esta concepção de aprendizagem docente temos as vozes de professores ${ }^{1}$.

[...] ao mesmo tempo em que a gente ensina a gente está aprendendo, então eu vejo como uma troca, eu cresço muito com meus alunos, eu aprendo com perguntas, com colocações, com vivências [...], com histórias de vida [...].

[...] eu acho que as turmas estão crescendo pelo fato de que a gente não tem tratado a questão do conhecimento de forma seqüencial, acho que vem crescendo porque estamos tendo um comportamento mais flexível com o conhecimento, como nós estamos mais flexíveis, mais abertos, o espaço de busca do aluno está mais aberto, flexível também [...]

[...] então eu chamo isso, que a aula tem de ser em tempo real e quando se faz isso você mesmo dentro da sala de aula pode criar, pode descobrir, pode reorganizar conhecimentos seu, porque você esta raciocinando na sala de aula, você não leva aula, você constrói seu raciocínio na hora, ai você mesmo se constrói, cada vez que você vai tratar de um assunto você descobre coisas novas, organiza, entende razoes que você ainda nunca tinha entendido [...].

Nesse diálogo, as narrativas dos professores explicitam outro conceito basilar - conhecimento compartilhado - que envolve as noções de aprendizagem colaborativa e de aprendizagem docente colaborativa. A primeira pode ser compreendida a partir da dinâmica das trocas entre pares/docentes/discentes, o que implica a autonomia dos sujeitos envolvidos nesse processo, permitindo-lhes, a partir da reestruturação individual dos seus esquemas de conhecimento, resolver diferentes situações didático-pedagógicas e profissionais. O compartilhar

\footnotetext{
As vozes foram destacadas a partir de pesquisas desenvolvidas pelas autoras. Cada excerto narrativo será acompanhado da letra $\mathrm{P}$, designando a manifestação de um professor, sujeito das pesquisas exploradas neste texto. As pesquisas apoiada pelo CNPq e FAPERGS, são: Aprendizagem Docente e Processos Formativos: novas perspectivas para a educação básica e superior. Projeto de Pesquisa Interinstitucional e Integrado GAP n. 020117, CNPq e FAPERGS, 2007-2009, Centro de Educação/UFSM e Ciclos de vida profissional de professores do ensino superior: um estudo comparativo sobre trajetórias docentes. Projeto de Pesquisa - CNPq, 2007b - 2010.
}

Rev. Diálogo Educ., Curitiba, v. 10, n. 29, p. 13-26, jan./abr. 2010 
de ideias, inquietações, dúvidas e ajuda pressupõe atividades colaborativas, favorecendo o avanço do processo formativo em andamento (BOLZAN, 2002, 2007, 2008; BOLZAN; ISAIA, 2006, 2007). A segunda é entendida como o processo pelo qual o professor apreende a partir da análise e da interpretação de sua própria atividade e dos demais via compartilhamento de ideias, saberes e fazeres. Implica atividade conjunta e pressupõe um processo interdiscursivo e intersubjetivo, pois é através dessa relação plural, interativa e mediacional que a aprendizagem se dá, envolvendo um movimento de construção e reconstrução de ideias e premissas advindas do processo de compartilhamento (ISAIA, 2007a; BOLZAN; ISAIA, 2007, 2008).

Neste sentido, as falas/vozes assim manifestam-se:

[...] hoje considero o "ser professor" o centro da minha vida profissional. Acho que muitas coisas estão mudando e tantas outras ainda vão mudar. Atuo como docente em função dos alunos, a interação com eles é o meu principal motivador. E das discordâncias com os colegas, tiro muitas lições. Acho que o principal atributo de um professor é a capacidade de considerar alternativas. E isso não é nada fácil. Mas, como já disse anteriormente, ninguém disse que seria [...].

[...] Devemos encontrar um modo de trocarmos idéias com os colegas sobre as disciplinas lecionadas, sobre o planejamento das aulas, a forma e a metodologia utilizada para lidar com certos conteúdos, sempre buscando um objetivo comum $[\ldots]$

[...] minhas aulas mudaram muito, a gente aprendeu novos conceitos e novas metodologias, teve novos entendimentos e a troca com os colegas é muito rica [...]

Dessa forma, a aprendizagem docente tem o conhecimento profissional compartilhado e a aprendizagem colaborativa como elementos fundantes evidenciados nas falas/vozes que seguem:

[...] eu vejo que o aluno é um elemento marcante para nós, porque ele faz um crescimento em quatro anos, a gente acompanha o processo deles e a gente vê as transformações importantes e isso sempre reflete em nós de alguma maneira, faz a gente amadurecer.

Rev. Diálogo Educ., Curitiba, v. 10, n. 29, p. 13-26, jan./abr. 2010 
[...] eu fui aprendendo outro jeito de ensinar e aprender que era mais perto do meu jeito [...] em pequenos grupos, tendo parcerias que eu gosto muito de trocar. Eu sozinho não gosto. Acho até que a minha profissão tem muito a ver com isso [...] é uma troca, um relacionamento [...] [...] meu interesse maior é que o aluno adquira o hábito de pensar, entenda o que ele está aprendendo [...]

A partir de nossas colocações e em sintonia com as falas docentes enfatizamos que não é possível falarmos em um aprender generalizado de ser professor, mas entendê-lo a partir do contexto de cada docente no qual são consideradas suas trajetórias de formação e a atividade formativa para a qual se direcionam (ISAIA, 2007a, 2008).

Nessa direção, discutir a aprendizagem de ser professor exigenos entendê-la a partir de seus movimentos construtivos que se constituem como um conjunto de movimentos produzidos pelo docente à medida que ele atua. Essa atividade é marcada pelas trajetórias formativas que são incorporadas à docência a partir da tomada de consciência das dimensões pessoais e profissionais que permeiam tal processo. Os diferentes movimentos construtivos dos professores dependem da interação e dos processos formativos que eles colocam em andamento e da própria aprendizagem da docência que os acompanha ao longo de toda a carreira, não há linearidade nesse processo; esses movimentos correspondem a momentos de ruptura ou oscilação, responsáveis pelo aparecimento de novos percursos que podem ser por eles trilhados (ISAIA, 2007a, 2008; BOLZAN, 2005, 2008; BOLZAN; ISAIA, 2006, 2007; ISAIA; BOLZAN, 2007, 2008).

Portanto, o entrelaçamento dessas noções nos remete à ideia de processo formativo docente, que envolve um sistema organizado no qual participam tanto os sujeitos que se preparam para suas profissões quanto aqueles que já estão engajados na docência. É um processo de natureza social, no qual os esforços de aquisição, desenvolvimento e aperfeiçoamento de competências profissionais subentendem um grupo interagindo, centrado em interesses e necessidades comuns (ISAIA, 2006b).

A instauração desse processo pode ser construída a partir da reflexão conjunta entre professores tanto na formação inicial como na continuada. Para a constituição profissional docente é necessária a articulação entre ambiência pessoal e institucional, permitindo ao

Rev. Diálogo Educ., Curitiba, v. 10, n. 29, p. 13-26, jan./abr. 2010 
docente ler as diferentes realidades nas quais se encontra e a lidar com elas, aceitando a si mesmo, aos outros e ao mundo como desafios permanentes e expandindo, assim, o seu potencial gerativo em um continuum de experienciação-expressão (L'ABATE, 1994; MACIEL, 2000, 2009a, 2009b). Dessa forma, as vozes trazidas expressam a construção do processo formativo dos professores:

[...] a universidade, eu acho que é um local que a gente tem para trocar o máximo de experiências, talvez seja um local que a gente nunca alcance, nuca esgote essa fonte de conhecimentos [...].

[...] devemos encontrar um modo de trocarmos idéias com os colegas sobre as disciplinas lecionadas, sobre o planejamento das aulas, a forma e a metodologia utilizada para lidar como certos conteúdos, sempre buscando um objetivo comum [...].

[...] a ajuda, a solidariedade, a interdisciplinaridade. Não é só troca de conteúdos, mas ela só acontece na perspectiva do contexto de envolvimento mútuo, não podemos perder a referência de que isso é um trabalho conjunto $[\ldots]$.

O processo formativo, assim constituído, caracteriza-se por diferentes movimentos construtivos que permitem explicitar o aparecimento de novos percursos a serem trilhados pelos docentes. Tais percursos nos possibilitam compreender como a professoralidade se produz. Sua dinâmica constitutiva orienta-se para a reflexão como componente intrínseco ao processo de ensinar, de aprender, de formarse e, consequentemente, de desenhar sua própria trajetória profissional, envolvendo as ideias de conhecimento pedagógico compartilhado e redes de interações. Esse conhecimento se caracteriza como um sistema de ideias com distintos níveis de concretude e articulação, apresentando dimensões dinâmicas de caráter processual, pois implica em uma rede de interações consubstanciada nas relações interpessoais. Organiza-se com variedade e riqueza, apresentando quatro dimensões: o conhecimento teórico e conceitual, a experiência prática do professor, a reflexão sobre a ação docente e a transformação da ação pedagógica. O processo de constituição desse conhecimento implica na reorganização contínua dos saberes pedagógicos, teóricos e práticos,

Rev. Diálogo Educ., Curitiba, v. 10, n. 29, p. 13-26, jan./abr. 2010 
da organização das estratégias de ensino, das atividades de estudo e das rotinas de trabalho dos docentes, onde o novo se elabora a partir do velho, mediante ajustes desses sistemas (BOLZAN, 2002, p. 151).

Tal perspectiva pode ser percebida nas vozes dos professores:

[...] meu trabalho como professor, o que eu gosto de fazer, é um trabalho de formação. Construir, colocar o primeiro tijolo num edifício e não colocar os últimos tijolos [...].

[...] Em especifico nas aulas o que esta em questão é como e onde o conhecimento em discussão será empregado. Qual a utilidade daquele saber e que implicações com outras áreas e atuações ele tem ou poderá ter [...].

Assim, o professor à medida que ensina aprende com seus alunos, denotando espírito de abertura e humildade ao não adotar uma posição autoritária, ao mesmo tempo em que está ciente de sua responsabilidade em conduzir o processo formativo, assumindo sua professoralidade docente.

\section{Relações e novos sentidos para a docência universitária}

Para ser possível compreender os processos formativos em andamento, é necessário levar em conta a desestabilização crescente das ações docentes, colocando o sujeito professor em permanente processo de reorganização pedagógica pela reflexão, favorecendo a aprendizagem de ser professor.

As relações e os novos sentidos da pedagogia universitária caracterizam-se por um conjunto de dimensões que permeiam o processo de produção da docência, permitindo apreender as manifestações dos atos e das formas de inserção no mundo da docência (BOLZAN, 2008), enfocando o processo de construção da professoralidade.

Logo, a elaboração de uma pedagogia universitária pressupõe o processo de aprendizagem docente na medida em que os professores precisam conscientizar-se da inter-relação teoria/prática. As teorizações, via de regra, requerem a incorporação de ferramentas conceituais para questionar tanto a teoria quanto a prática e não para configurá-las. Cabe ao professor não só considerar a dinâmica relacional teoria/prática no processo de profissionalização discente como também incorporá-la ao seu processo de apreender a docência. Isso não significa que o professor

Rev. Diálogo Educ., Curitiba, v. 10, n. 29, p. 13-26, jan./abr. 2010 
não tenha que organizar os processos formativos para dar conta da aula através de estudos teóricos, mas ele precisa compreender que a prática educativa implica uma prática social, acadêmica e pedagógica. Por isso, sustentamos a ideia de produzir uma pedagogia específica para o ensino superior, que inclua a reflexão sobre a prática como um núcleo fundamental, no qual indagar-se sobre as ações tomadas e suas relações com as teorias e os problemas emergentes da prática possibilitam o avanço e a formulação de novos conhecimentos.

Portanto, acreditamos em um processo de formação comprometido com a transformação das ações que integra e articula os caminhos que a ação docente tomará, validando as ações pedagógicas pensadas, os problemas e suas dimensões, a dinamização das inovações, enfim, a definição dos critérios de mudanças, de propostas e de alternativas pedagógicas capazes de maximizar o processo de construção da professoralidade.

Sabemos que os processos formativos se constituem em atividades coletivas, mas não necessariamente ocorrem de forma compartilhada. A proposição de um trabalho compartilhado implica a ruptura da visão sectária e individual na formação, de maneira que o trabalho pedagógico seja organizado considerando os tempos e os espaços pedagógicos a serem vivenciados pelos sujeitos envolvidos no processo formativo em andamento.

Precisa haver uma priorização dos trabalhos coletivos, bem como a valorização de espaços de aprendizagens comuns. A discussão de situações concretas vividas no contexto das aulas colabora para a implementação de trabalho em equipes, fortalecendo os laços de confiança e cooperação, proporcionando, desse modo, um aporte importante para a construção de conhecimento pedagógico compartilhado.

Nessa dinâmica, o processo sistemático de reflexão pode pôr em jogo as ações docentes a serem implementadas, fortalecendo os critérios de escolha das atividades pedagógicas. Assim, a ênfase na figura do docente como profissional reflexivo em contextos nos quais as orientações pedagógicas são discutidas e analisadas, permite avanços na construção do conhecimento pedagógico compartilhado.

Um aspecto importante a destacar ainda diz respeito à busca de um desenho alternativo de atividades pedagógicas que proporcionem a interação entre os sujeitos, de modo que as tomadas de decisão, o pensamento crítico, a autonomia crescente, o manejo de variadas informações e a elaboração de estratégias sejam fontes de protagonismo pedagógico. E, ao mesmo tempo em que favoreçam a compreensão das diversidades dos sujeitos em processo formativo e dos contextos culturais aos quais estão vinculados.

Rev. Diálogo Educ., Curitiba, v. 10, n. 29, p. 13-26, jan./abr. 2010 
Os processos formativos específicos para docência na educação superior são inexistentes. Os estudos de Isaia (2001, 2003, 2004, 2005, 2006a) e Isaia e Bolzan (2005, 2006b, 2007, 2008) indicam a prevalência de uma formação voltada ao saber fazer ou ao saber técnico na formação de educadores da Educação Básica, deixando evidente que o docente universitário não tem formação pedagógica para atuar na formação profissional de outros sujeitos.

Essa prevalência na docência universitária marca, de certa forma, uma negação dos processos de pensamento necessários ao planejamento e à ação docente para esse nível de ensino.

As pesquisas desenvolvidas têm indicado ausência de domínio de um saber organizacional pedagógico dos conteúdos específicos a serem trabalhados. Há uma evidente ausência de um saber pedagógico capaz de promover atividades de compartilhamento e colaboratividade no processo de ensino e de aprendizagem. Há também uma clara dificuldade de avaliar o desempenho dos profissionais em formação, além do próprio desempenho docente. E, ainda, os docentes manifestam que têm dificuldades de produzir estratégias capazes de promover o avanço cognitivo de seus alunos pela apropriação dos conhecimentos necessários à profissionalização (ISAIA; BOLZAN, 2005, 2006a, 2006b, 2007, 2008).

Pois bem, a formação não é somente prática nem somente teoria, mas consiste também nos discursos assumidos e nas relações estabelecidas identificadas pelos "jeitos de ser e fazer-se docente" dentro da cultura universitária.

Nesse sentido, a aula universitária apresenta-se como um lugar no qual são assumidas ideias, comportamentos e ações que podem ser apropriados a partir das regras produzidas nesse espaço sociocultural, permitindo aos docentes e aos futuros profissionais que sejam capazes de enfrentarem situações conhecidas que se reproduzem ou problemas novos e desconhecidos a serem experimentados.

Portanto, a pedagogia universitária pode ser compreendida como um espaço em movimento, no qual podemos analisar e compreender os fenômenos de aprender e de ensinar as profissões, sobretudo, um espaço no qual a própria docência universitária em ação pode ser revisitada e constantemente reconstruída.

Nesse sentido, a universidade precisa ser entendida como lugar de formação no qual a organização pedagógica precisa ser articulada de maneira criativa, constituindo-se num centro de inovação no qual o protagonismo pedagógico é reconhecido como caminho para emancipação dos processos formativos e da aprendizagem docente e, consequentemente, da professoralidade.

Rev. Diálogo Educ., Curitiba, v. 10, n. 29, p. 13-26, jan./abr. 2010 


\section{REFERÊNCIAS}

BOLZAN, D. P. V. A construção do conhecimento pedagógico compartilhado: um estudo a partir de narrativas de professoras do ensino fundamental. 2001. 280 f. Tese (Doutorado em Educação) - Universidade Federal Rio Grande do Sul, Faculdade de Educação, Porto Alegre, 2001.

Formação de professores: compartilhando e reconstruindo conhecimentos. Porto Alegre: Mediação, 2002.

A construção do conhecimento pedagógico compartilhado: reflexões sobre o papel do professor universitário. In: SEMINÁRIO DE PESQUISA EM EDUCAÇÃO DA REGIÃO SUL, 5., 2004, Curitiba. Anais... Curitiba: PUCPR, 2004. p. 1-12.

Atividade discursiva como elemento mediador na construção do conhecimento pedagógico compartilhado. In: ALONSO, C. M. M. C. (Org.). Reflexões sobre políticas educativas. ENCONTRO INTERNACIONAL DE PESQUISADORES DE POLÍTICAS EDUCATIVAS, 1., Santa Maria. Anais... Santa Maria: AUGM, 2005. p. 117-128.

. Verbetes. In: CUNHA, M. I.; ISAIA, S. Professor da educação superior. In: MOROSINI, M. (Ed.). Enciclopédia de pedagogia universitária glossário. Brasília: INEP, 2006. v. 2, p. 380.

Aprendizagem docente e processos formativos: novas perspectivas para a educação básica e superior. (Projeto de Pesquisa Interinstitucional e Integrado), GAP nº. 020117. Centro de Educação/UFSM, Santa Maria/RS, 20072009.

Pedagogia universitária e processos formativos: a construção do conhecimento pedagógico compartilhado. In: EGGERT, E. et al. (Org.). Trajetórias e processos de ensinar e aprender: didática e formação de professores. Porto Alegre: EDIPUCRS, 2008. p. 102-120.

BOLZAN, D. P. V.; ISAIA, S. M. de A. Aprendizagem docente na educação superior: construções tessituras da professoralidade. Revista Educação, Porto Alegre, ano 29, v. 3, n. 60, p. 489-501, 2006.

O conhecimento pedagógico compartilhado no processo formativo do professor universitário: reflexões sobre a aprendizagem docente. In: CONGRESSO INTERNACIONAL DE EDUCAÇÃO, 5.; CONGRESSO INTERNACIONAL DE EDUCAÇÃO - PEDAGOGIAS (ENTRE) LUGARES E SABERES, 5., 2007, São Leopoldo. Anais... São Leopoldo, UNISINOS, 2007. p. 1-12.

Rev. Diálogo Educ., Curitiba, v. 10, n. 29, p. 13-26, jan./abr. 2010 
ISAIA, S. Professor universitário no contexto de suas trajetórias como pessoa e profissional. In: MOROSINI, M. (Org.). Professor do ensino superior: identidade, docência e formação. 2. ed. Brasília: Plano, 2001. p. 35-60.

Formação do professor de ensino superior: tramas na tessitura. In: MOROSINI, M. (Org.). Enciclopédia de pedagogia universitária. Porto Alegre: FAPERGS/RIES, 2003. p. 241-251.

. Aprendizagem na docência superior? Desafios para a formação de professores. In: SEMINÁRIO DE PESQUISA EM EDUCAÇÃO DA REGIÃO SUL, 5., 2004, Curitiba. Anais... Curitiba: PUCPR, 2004. p. 1-12.

Ciclos de vida profissional docente: delineamento teórico-metodológico específico para professores do ensino superior. In: ALONSO, C. M. M. C. (Org.). Reflexões sobre políticas educativas. Santa Maria: UFSM/AUGM, 2005. p. 35-44.

Desafios à docência superior: pressupostos a considerar. In: RISTOFF, D.; SEVEGNANI, P. (Org.). Docência na educação superior. Brasilia: INEP, 2006a. p. 65-86. (Coleção Educação Superior em Debate; v. 5).

Verbetes. In: CUNHA, M. I.; ISAIA, S. Professor da educação superior. In: MOROSINI, M. (Ed.). Enciclopédia de pedagogia universitária glossário. Brasília: INEP, 2006b. p. 351-377.

Aprendizagem docente como articuladora da formação e do desenvolvimento profissional dos professores da Educação Superior. In: ENGERS, M. E.; MOROSINI, M. (Org.). Pedagogia universitária e aprendizagem. Porto Alegre: EDIPUCRS, 2007a. v. 2, p. 153-165.

Ciclos de vida profissional de professores do ensino superior: um estudo comparativo sobre trajetórias docentes. Projeto de Pesquisa - CNPq, $2007 \mathrm{~b}$.

Aprendizagem docente: sua compreensão a partir das narrativas de professores. In: TRAVERSINI, C. et al. Trajetórias e processos de ensinar e aprender: práticas e didáticas. Porto Alegre: EDIPUCRS, 2008. p. 618-635.

ISAIA, S.; BOLZAN, D. P. V. Aprendizagem docente no ensino superior: construções a partir de uma rede de interações. In: CONGRESSO INTERNACIONAL DE EDUCAÇÃO, 1., 2007, São Leopoldo. Anais... São Leopoldo: UNISINOS, 2005. p.1-13.

Construção da profissão docente/professoralidade em debate: desafios para a educação superior. In: CUNHA, M. I. (Org.). Reflexões e práticas em pedagogia universitária. Campinas: Papirus, 2007. p. 161-177.

Compreendendo os movimentos construtivos da docência superior: construções sobre pedagogia universitária. Linhas Críticas, Brasília, v. 14, n. 26, p. $43-59,2008$.

Rev. Diálogo Educ., Curitiba, v. 10, n. 29, p. 13-26, jan./abr. 2010 
LUCARELLI, E. Pedagogia universitária e inovação. In: CUNHA, M. I. (Org.). Reflexões e práticas em pedagogia universitária. Campinas: Papirus, 2007. p. 11-26.

L'ABATE, L. A theory of personality development. New York: John Wiley \& Sons, 1994.

MACIEL, A. M. R. Formação na docência universitária? Realidade e possibilidades a partir do contexto da Universidade de Cruz Alta. 2000. 226 f. Tese (Doutorado Em Educação) - Universidade Estadual de Campinas, Campinas, SP, 2000.

A geratividade docente na educação superior e os movimentos (trans) formativos para o desenvolvimento profissional. In: ISAIA, S.; BOLZAN, D. (Org.). Pedagogia universitária: desenvolvimento profissional docente. Porto Alegre: EDIPUCRS, 2009a. v. 4, p. 281-298.

O processo formativo do professor no ensino superior: em busca de uma ambiência (trans) formativa. In: ISAIA, S. M. A.; BOLZAN, D. P.V.; MACIEL, A. M. R. (Org.). Pedagogia universitária: tecendo redes sobre a Educação Superior. Santa Maria: Ed. da UFSM, 2009b. p. 63-77.

MARCELO, C. Formación del profesorado para el cambio educativo. Barcelona: EUB, 1999.

Recebido: 14/08/2009

Received: 08/14/2009

Aprovado: 30/10/2009

Approved: 10/30/2009

Rev. Diálogo Educ., Curitiba, v. 10, n. 29, p. 13-26, jan./abr. 2010 